\title{
Retrograde solubility of formamidinium and methylammonium lead halide perovskites enabling rapid single crystal growth
}

Makhsud I. Saidaminov ${ }^{\mathrm{a}}$, Ahmed L. Abdelhady ${ }^{\mathrm{ab}}$, Giacomo Maculan $^{\mathrm{a}}$, \& Osman M. Bakr ${ }^{\mathrm{a}}$

${ }^{a}$ Division of Physical Sciences and Engineering, Solar and Photovoltaics Engineering Research Center, King Abdullah University of Science and Technology (KAUST), Thuwal 23955-6900, Kingdom of Saudi Arabia

${ }^{b}$ Department of Chemistry, Faculty of Science, Mansoura University, Mansoura, 35516, Egypt

*Corresponding author, email: osman.bakr@kaust.edu.sa 
Here we show the retrograde solubility of various hybrid perovskites through the correct choice of solvent(s) and report their solubility curves. Retrograde solubility enables to develop inverse temperature crystallization of $\mathrm{FAPbX}_{3}\left(\mathrm{FA}=\mathrm{HC}\left(\mathrm{NH}_{2}\right)_{2}{ }^{+}, \mathrm{X}=\mathrm{Br}^{-} / \mathrm{I}^{-}\right)$based on retrograde solubility. $\mathrm{FAPbI}_{3}$ crystals exhibit a $1.4 \mathrm{eV}$ bandgap - considerably narrower than their polycrystalline counterparts.

Pioneering works on utilizing hybrid perovskites in photovoltaics ${ }^{1-3}$ drew the attention of many researchers to this promising class of semiconductors, which possess strong and tunable absorptions and emissions, ${ }^{4}$ as well as remarkable charge-carrier diffusion lengths. ${ }^{5}$ Combined with the facile and low-cost deposition methods, ${ }^{6-9}$ these properties thrust perovskites to the forefront of modern optoelectronic semiconductor devices such as solar cells, ${ }^{10-17}$ photodetectors, ${ }^{18-20}$ light emitting diodes, ${ }^{21}$ lasers, ${ }^{22}$ X-ray detectors ${ }^{23}$ and ambipolar phototransistors. ${ }^{24}$ The optical properties of hybrid perovskites, such as $\mathrm{MAPbX}_{3}$ and $\mathrm{FAPbX}_{3}$ (where MA $=\mathrm{CH}_{3} \mathrm{NH}_{3}{ }^{+}$, and $\mathrm{FA}=\mathrm{HC}\left(\mathrm{NH}_{2}\right)_{2}{ }^{+}$and $\mathrm{X}=\mathrm{Cl}^{-}, \mathrm{Br}^{-}, \mathrm{I}^{-}$), show an astonishing sensitivity to their compositions. For instance, in the widely investigated $\mathrm{MAPbX}_{3}$, the substitution of $\mathrm{Cl}^{-}$with $\mathrm{Br}^{-}$or $\mathrm{I}^{-}$narrows the bandgap from 3.11 to 2.35 or $1.6 \mathrm{eV}$, respectively. ${ }^{25,26}$ Although $\mathrm{MAPbI}_{3}$ is thoroughly exploited as an active/absorber layer in solar cells, its bandgap is still significantly larger than the optimum for a single-junction solar cell $(\sim 1.34 \mathrm{eV}) .^{27}$

A further narrowing of the perovskite bandgap was demonstrated through the replacement of the small MA (1.8 $\AA$ ) cation with a larger FA (1.9-2.2 $\AA$ ) cation, forming FAPbX 3 ; in polycrystalline thin films, the bandgap was reduced from $1.6 \mathrm{eV}$ to $1.48 \mathrm{eV},{ }^{28-30}$ indicating a potentially higher power conversion efficiency (PCE) of $\mathrm{FAPbI}_{3}$-based solar cells. For this reason, $\mathrm{FAPbI}_{3}$ is actively replacing $\mathrm{MAPbX}_{3}$ in the most efficient perovskite solar cells ${ }^{28-35}$, with $\mathrm{PCE}$ values reaching $20 \% .^{28}$

The overwhelming majority of perovskite devices are based upon polycrystalline thin films - a material that suffers immensely from a high density of traps and grain boundaries, which markedly limit the potential performance in devices. Recently, it was reported that hybrid perovskite single crystals display exceptionally low trap densities ( $\sim 6$ orders of magnitude less compared to their polycrystalline films). ${ }^{5,36}$ Therefore, higher crystallinity is an extremely desired criterion for the further improvement of perovskite-based device performances. However, the synthesis of perovskite crystals through the classical cooling ${ }^{37}$ or antisolvent vapor-assisted crystallization ${ }^{5}$ techniques is a time-consuming process that requires weeks to prepare high-quality crystals. Recently, we reported a rapid inverse temperature crystallization (ITC) method for $\mathrm{MAPbX}_{3}{ }^{36}$ This method takes advantage of the retrograde solubility regime a peculiar regime in which the loss of solubility occurs in a specific solvent or solvents at elevated temperatures. ${ }^{36,38,39}$ However, the retrograde solubility of the highly desired FA-based perovskites has thus far not been reported. Retrograde solubility enables a facile and rapid route 
to grow crystals, and if established in $\mathrm{FAPbX}_{3}$, could allow for a more extensive use of this emerging subclass of hybrid perovskites, not only with regards to fundamental aspects but also in the practical design of optoelectronic devices.

Normally that salts possess higher solubilities at elevated temperatures. Remarkably, we observed the formation of perovskite precipitates in specific solvents at elevated temperatures, which is an indication of retrograde solubility. Nevertheless, this abnormal retrograde solubility behavior was noted for few salts. ${ }^{40}$ To confidently validate the retrograde solubility behavior of the hybrid perovskites, we tested their solubilities in various solvents at different temperatures and determined that $\gamma$-butyrolactone (GBL) is generally a suitable solvent for I-based perovskites, whereas the more polar $N, N$-dimethylformamide (DMF) is the proper solvent for the Br-based ones. The effect of the temperature on the solubility of methylammonium and formamidinium lead halides is shown in Figure 1. The negative slopes of the curves clearly confirmed the retrograde solubility behavior of the perovskites in the mentioned solvents.
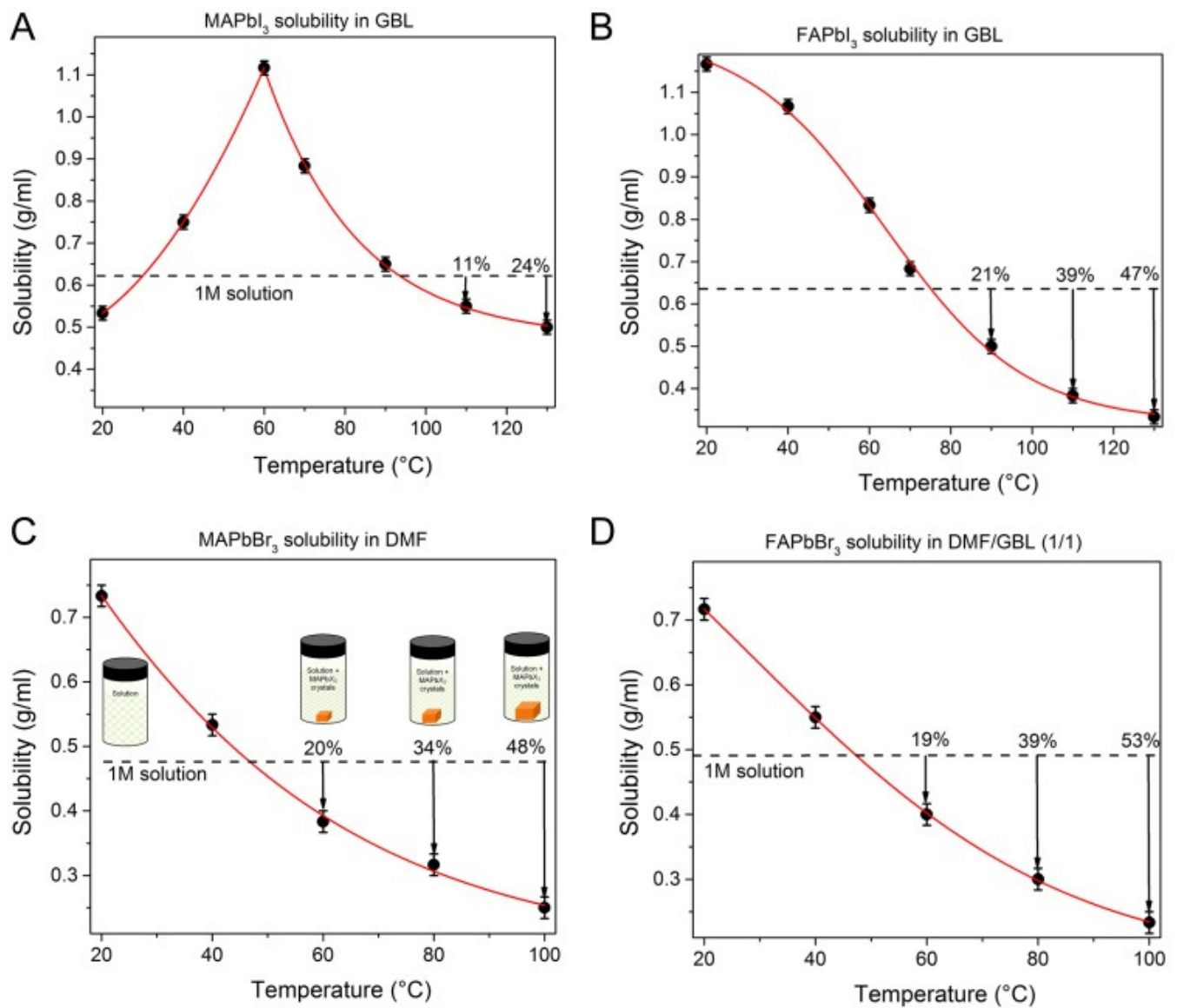

Fig. 1 Temperature-dependent solubility of (A) MAPbl in GBL and (B) FAPbl ${ }_{3}$ in GBL, (C) $M A P b B r_{3}$ in $\mathrm{DMF}_{3}$ showing yield at different temperatures, (D) $\mathrm{FAPbBr}_{3}$ in $\mathrm{DMF}: \mathrm{GBL}(1: 1 \mathrm{v} / \mathrm{v})$, 
Importantly, individual precursors $\left(\mathrm{PbX}_{2}\right.$ or $\left.\mathrm{MAX}\right)$ in the corresponding solvents did not show retrograde solubility behavior. These two observations - retrograde solubility being tied to the whole perovskite and retrograde solubility dependence on solvent - indicate that the energetics of precursor-solvent complexes is likely to be responsible for this phenomenon. These complexes disassociate at elevated temperature, commencing crystallization.

Figure 1a shows the temperature-dependent solubility of the most widely used hybrid perovskite - $\mathrm{MAPbI}_{3}$ in GBL. Interestingly, the solubility of $\mathrm{MAPbI}_{3}$ in $\mathrm{GBL}$ increased with a corresponding increase in the temperature from $20{ }^{\circ} \mathrm{C}$ to $60{ }^{\circ} \mathrm{C}$; however, further heating resulted in the loss of solubility. The presence of both positive and negative slopes on the solubility curve indicates that there are two competing processes occurring in the solution during heating - the formation of complexes and their dissociation. At $\mathrm{T}<60{ }^{\circ} \mathrm{C}$, the complexes formation prevails, while at $\mathrm{T}>60{ }^{\circ} \mathrm{C}$, the complexes dissociation dominates over their formation. Remarkably, the solubility of $\mathrm{MAPbI}_{3}$ decreased by more than a factor of two with heating from $60{ }^{\circ} \mathrm{C}$ to $130{ }^{\circ} \mathrm{C}$. Recently, retrograde solubility enabled us to design a facile and rapid route to grow high-quality bulk $\mathrm{MAPbI}_{3}$ single crystals, ${ }^{36}$ and establishing this phenomenon in $\mathrm{FAPbI}_{3}$ will allow more extensive use of this emerging subclass of perovskite crystals.
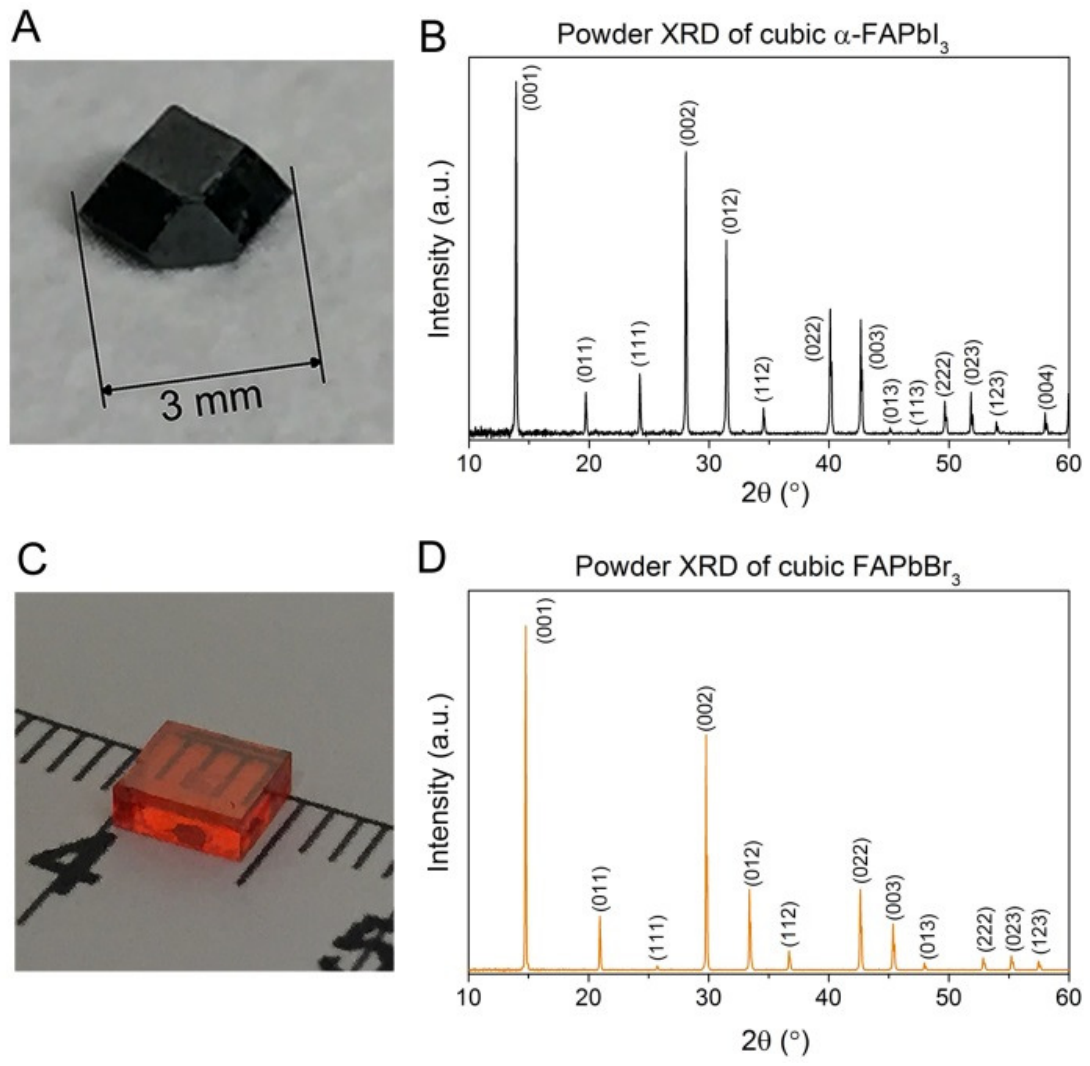

Fig. 2 Picture of (A) $\mathrm{FAPbl}_{3}$ crystal and its (B) powder XRD, picture of (C) $\mathrm{FAPbBr}_{3}$ crystal and its (D) powder XRD. 
Through the choice of suitable solvent, we found that a single GBL solvent can also be used to commence the retrograde solubility of $\mathrm{FAPbI}_{3}$ (Figure 1b); its solubility drops by more than three times with heating from $20{ }^{\circ} \mathrm{C}$ to $130{ }^{\circ} \mathrm{C}$. Further, we optimized the conditions to grow $\mathrm{FAPbI}_{3}$ by ITC. Using $1 \mathrm{M}$ solution of $\mathrm{FAPbI}_{3}$ in $\mathrm{GBL}$ at $100{ }^{\circ} \mathrm{C}$ frequently resulted in formation of needle-like yellow crystals, which gradually transforms to black crystals with mosaic morphology and many cracks. Due to stability of black phase at elevated temperatures ${ }^{30-32}$ we reasoned that higher temperature of crystallization could result in directly forming of black crystals. Therefore, we used $0.8 \mathrm{M}$ solution to increase the onset of crystallization temperature to $115^{\circ} \mathrm{C}$, and successfully grew crack- and grain boundary-free (Figure S1) black crystal in $3 \mathrm{~h}$ (Figure 2a) (see ESI for details). Powder XRD of freshly prepared crystals perfectly matches with previously reported cubic phase $\alpha-\mathrm{FAPbI}_{3}$ (Figure $2 \mathrm{~b}$ ). ${ }^{41}$ As reported, ${ }^{30-32}$ due to the instability of the black polymorph, it transformed to the yellow phase $\delta$-FAPbI ${ }_{3}$ (Figure S2) in air in $24 \mathrm{~h}$ and a humidity of $55-57 \%$.

We didn't observe the retrograde solubility behavior of I-based perovskites in more polar solvent - DMF or DMSO. We speculate that the lead iodide complexes with DMF or DMSO ${ }^{42}$ seem to be stronger compared to the GBL, which do not decompose in solution at elevated temperatures without evaporation of solvents.

In contrast, retrograde solubility behavior of Br-based perovskites was observed only in DMFbased solvents (Figure $1 \mathrm{c}, \mathrm{d}$ ). Figure 1c shows that the solubility of $\mathrm{MAPbBr}_{3}$ in $\mathrm{DMF}$ decreased significantly - almost by a factor of three, when it was heated from $20{ }^{\circ} \mathrm{C}$ to $100{ }^{\circ} \mathrm{C}$. Previously, we used a single solvent (DMF) for the ITC of MAPbBr ${ }_{3}{ }^{36}$ DMF can also be used as a sole solvent for $\mathrm{FAPbBr}_{3}$ synthesis by ITC; however, despite it forms a highly saturated solution in DMF at room temperature $(\sim 3.12 \mathrm{M})$, it produces only small crystals at $120^{\circ} \mathrm{C}$. The solubility of $\mathrm{FAPbBr}_{3}$ in DMF decreased only 1.7 times with heating from $20{ }^{\circ} \mathrm{C}$ to $100{ }^{\circ} \mathrm{C}$ (Figure S3). Therefore, to increase the yield of crystallization and to avoid over-consumption of the precursors, we reasoned that the dilution of the DMF polarity through mixing with the less polar GBL could increase the negative slope of the solubility curve. We found that the retrograde solubility behavior of $\mathrm{FAPbBr}_{3}$ can be initiated in a 1:1 v/v of DMF:GBL, while the solubility decreased by more than three times through an increase in the temperature from $20^{\circ} \mathrm{C}$ to $100{ }^{\circ} \mathrm{C}$. For ITC of $\mathrm{FAPbBr}_{3}$, we used $1 \mathrm{M}$ solution in 1:1 v/v DMF:GBL with crystallization onset at 55 ${ }^{\circ} \mathrm{C}$ to grow crack-free crystals (see ESI for details). Powder X-ray diffraction (XRD) of the $\mathrm{FAPbBr}_{3}$ ground crystals matched with the reported cubic phase of $\mathrm{FAPbBr}_{3}$ (Figure 2c,d). ${ }^{43}$

The yield of the crystallization - the ratio of the mass of the crystals to the precursors - can be estimated from the solubility curves (Figure 1). These curves also demonstrated that there are several ways to increase the yield: (1) the initial use of a higher precursors concentrations (Figure S4 validates this concept); and (2) the utilization of a higher crystallization temperature (Figure S5). In classical cooling and antisolvent vapor-assisted crystallization techniques, nonequimolar precursors (for instance, the ratio of $\mathrm{MAI}: \mathrm{PbI}_{2}$ is $3: 1$ for the antisolvent technique) ${ }^{5}$ or the presence of foreign additives (for example hydro-iodide acid in the classical cooling 
technique $)^{37}$ renders the leftover solution unusable. In contrast, the overconsumption of solvents and precursors is minimized in the ITC method because the depleted solution can be repeatedly used for crystallization by dissolving more precursors, due to the utilization of equimolar amounts of the precursors and the reduced requirement of the solvents.

Given the emergence of $\mathrm{FAPbX}_{3}$ as the perovskite of choice in solar cells, it is important to elucidate the optical bandgaps of their crystals, which have thus far not been reported. Having the macroscopic crystals, we studied the absorption of the $\mathrm{FAPbX}_{3}$ crystals (Figure 3). Very intriguingly, we observed that $\alpha-\mathrm{FAPbI}_{3}$ crystal absorbs the light efficiently up to $900 \mathrm{~nm}$, which is $80 \mathrm{~nm}$ broader than its polycrystalline counterpart (Figure S6). A Tauc plot shows that the bandgap of $\alpha-\mathrm{FAPbI}_{3}$ is $1.4 \mathrm{eV}$; this value is $70 \mathrm{meV}$ narrower than previous reports for this material. ${ }^{30,44}$ Analogously, the absorption edge of $\mathrm{FAPbBr}_{3}$ was found to be located at $580 \mathrm{~nm}$, corresponding to a bandgap of $2.13 \mathrm{eV}, 130 \mathrm{meV}$ narrower than that of the $\mathrm{FAPbBr}_{3}$ polycrystalline thin film (Figure S6). ${ }^{43}$ Narrowing of bandgap in $\mathrm{MAPbX}_{3}$ single crystals compared to its polycrystalline films was also observed before, which was attributed to lower trap densities due to a higher-dimensional structurally coherent units that are more tight in the single crystal compared to their polycrystalline counterparts. ${ }^{5,19,36}$ Hence, single crystals provide the ideal platform to extract the real bandgap. For the best of our knowledge, this is the first demonstration of $1.4 \mathrm{eV}$ bandgap of $\alpha-\mathrm{FAPbI}_{3}$. Our findings indicate that devices based upon $\alpha$ $\mathrm{FAPbI}_{3}$ crystals may deliver higher efficiencies than their polycrystalline thin films owing to their broader absorption of solar spectrum.
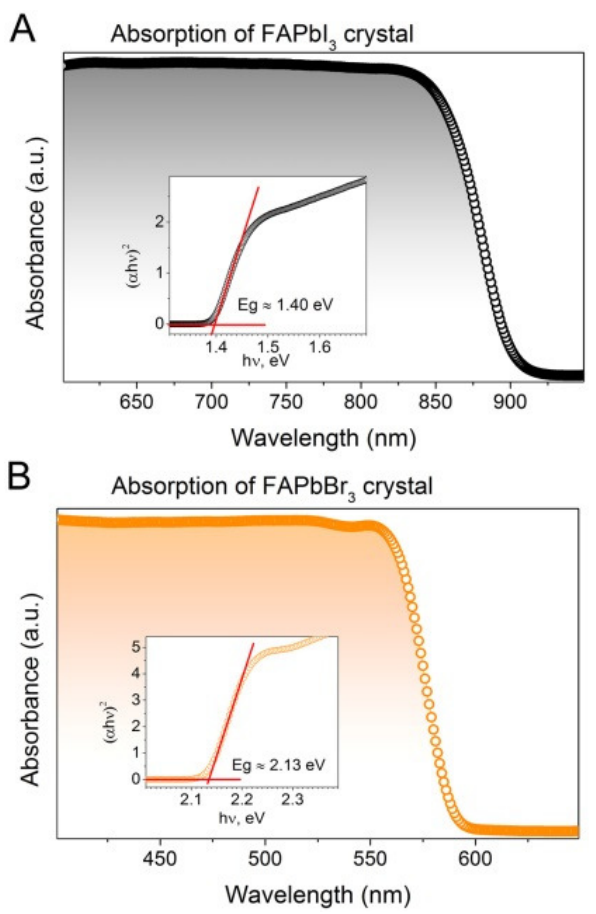

Fig. 3 Absorption spectrum of (A) $\mathrm{FAPbl}_{3}$ and (B) $\mathrm{FAPbBr}_{3}$ crystals. Insets: corresponding Tauc plots to extract the bandgaps. 
In summary, we demonstrated the temperature-dependent solubility of hybrid organolead halide perovskites. We showed that the retrograde behavior and ITC is not limited to $\mathrm{MAPbX}_{3}$ perovskites but could be generalized, by solvent selection, to $\mathrm{FAPbX}_{3}$. Grown crystals of $\mathrm{FAPbI}_{3}$ exhibited a $1.4 \mathrm{eV}$ bandgap, which was significantly lower than that of their polycrystalline counterpart. These findings provide an additional impetus to improve the crystallinity of $\mathrm{FAPbI}_{3}$ for further enhancements in solar cell efficiencies.

\section{Acknowledgements}

The authors acknowledge the support of Awards URF/1/2268-01-01, URF/1/1741-01-01, and URF/1/1373-01-01 made by King Abdullah University of Science and Technology (KAUST).

\section{Notes and references}

1. A. Kojima, K. Teshima, Y. Shirai and T. Miyasaka, J. Am. Chem. Soc., 2009, 131, 60506051.

2. J. H. Im, C. R. Lee, J. W. Lee, S. W. Park and N. G. Park, Nanoscale, 2011, 3, 40884093.

3. H. Yum, J. E. Moser, M. Gratzel and N. G. Park, Sci. rep., 2012, 2, 591.

4. M. Zhang, H. Yu, M. Lyu, Q. Wang, J.-H. Yun and L. Wang, Chem. Commun., 2014, 50, 11727-11730.

5. D. Shi, V. Adinolfi, R. Comin, M. Yuan, E. Alarousu, A. Buin, Y. Chen, S. Hoogland, A. Rothenberger, K. Katsiev, Y. Losovyj, X. Zhang, P. A. Dowben, O. F. Mohammed, E. H. Sargent and O. M. Bakr, Science, 2015, 347, 519-522.

6. N. Yantara, D. Sabba, Y. Fang, J. M. Kadro, T. Moehl, P. P. Boix, S. G. Mhaisalkar, M. Gratzel and C. Gratzel, Chem. Commun., 2015, 51, 4603-4606.

7. G. Longo, L. Gil-Escrig, M. J. Degen, M. Sessolo and H. J. Bolink, Chem. Commun., 2015, 51, 7376-7378.

8. X. Cui, K. Jiang, J.-H. Huang, X. Zhou, M. Su, S.-G. Li, Q.-Q. Zhang, L.-M. Yang and Y. Song, Chem. Commun., 2014, 51, 1457-1460.

9. B. R. Sutherland, S. Hoogland, M. M. Adachi, P. Kanjanaboos, C. T. O. Wong, J. J. McDowell, J. Xu, O. Voznyy, Z. Ning, A. J. Houtepen and E. H. Sargent, Adv. Mater., 2014, 27, 53-58.

10. M. Ibrahim Dar, M. Abdi-Jalebi, N. Arora, T. Moehl, M. Gratzel and M. K. Nazeeruddin, Adv. Mater., 2015, DOI: 10.1002/adma.201503124. 
11. W. Nie, H. Tsai, R. Asadpour, J.-C. Blancon, A. J. Neukirch, G. Gupta, J. J. Crochet, M. Chhowalla, S. Tretiak, M. A. Alam, H.-L. Wang and A. D. Mohite, Science, 2015, 347, 522-525.

12. C. Eames, J. M. Frost, P. R. Barnes, B. C. O'Regan, A. Walsh and M. S. Islam, Nat. Commun., 2015, 6, 7497.

13. N. J. Jeon, J. H. Noh, Y. C. Kim, W. S. Yang, S. Ryu and S. I. Seok, Nat. Mater., 2014, 13, 897-903.

14. M. M. Lee, J. Teuscher, T. Miyasaka, T. N. Murakami and H. J. Snaith, Science, 2012, 338, 643-647.

15. D. Liu, J. Yang and T. L. Kelly, J. Am. Chem. Soc., 2014, 136, 17116-17122.

16. J. Xu, A. Buin, A. H. Ip, W. Li, O. Voznyy, R. Comin, M. Yuan, S. Jeon, Z. Ning, J. J. McDowell, P. Kanjanaboos, J.-P. Sun, X. Lan, L. N. Quan, D. H. Kim, I. G. Hill, P. Maksymovych and E. H. Sargent, Nat. Commun., 2015, 6, 7081.

17. A. H. Ip, L. N. Quan, M. M. Adachi, J. J. McDowell, J. Xu, D. H. Kim and E. H. Sargent, Appl. Phys. Lett., 2015, 106, 143902.

18. B. R. Sutherland, A. K. Johnston, A. H. Ip, J. Xu, V. Adinolfi, P. Kanjanaboos and E. H. Sargent, ACS Photonics, 2015, 2, 1117-1123.

19. G. Maculan, A. D. Sheikh, A. L. Abdelhady, M. I. Saidaminov, M. A. Haque, B. Murali, E. Alarousu, O. F. Mohammed, T. Wu and O. M. Bakr, J. Phys. Chem. Lett., 2015, 6, 37813786.

20. M.I. Saidaminov, V. Adinolfi, R. Comin, A.L. Abdelhady, W. Peng, I. Dursun, M. Yuan, S. Hoogland. E.H. Sargent and O.M. Bakr., Nat. Commun., 2015, 6, 8724.

21. Z. K. Tan, R. S. Moghaddam, M. L. Lai, P. Docampo, R. Higler, F. Deschler, M. Price, A. Sadhanala, L. M. Pazos, D. Credgington, F. Hanusch, T. Bein, H. J. Snaith and R. H. Friend, Nat. Nanotechnol., 2014, 9, 687-692.

22. H. Zhu, Y. Fu, F. Meng, X. Wu, Z. Gong, Q. Ding, M. V. Gustafsson, M. T. Trinh, S. Jin and X. Y. Zhu, Nat. Mater., 2015, 14, 636-642.

23. S. Yakunin, M. Sytnyk, D. Kriegner, S. Shrestha, M. Richter, G. J. Matt, H. Azimi, C. J. Brabec, J. Stangl, M. V. Kovalenko and W. Heiss, Nat. Photon, 2015, 9, 444-449.

24. F. Li, Ch. Ma, H. Wang, W. Hu, W. Yu, A.D. Sheikh, T. Wu. Nat. Commun., 2015, 6, 8238 .

25. T. Baikie, N. S. Barrow, Y. Fang, P. J. Keenan, P. R. Slater, R. O. Piltz, M. Gutmann, S. G. Mhaisalkar and T. J. White, J. Mater. Chem. A, 2015, 3, 9298-9307. 
26. J. Burschka, N. Pellet, S. J. Moon, R. Humphry-Baker, P. Gao, M. K. Nazeeruddin and M. Gratzel, Nature, 2013, 499, 316-319.

27. W. Shockley and H. J. Queisser, J. Appl. Phys., 1961, 32, 510-519.

28. W. S. Yang, J. H. Noh, N. J. Jeon, Y. C. Kim, S. Ryu, J. Seo and S. I. Seok, Science, 2015, 348, 1234-1237.

29. J.-W. Lee, D.-J. Seol, A.-N. Cho and N.-G. Park, Adv. Mater., 2014, 26, 4991-4998.

30. N. J. Jeon, J. H. Noh, W. S. Yang, Y. C. Kim, S. Ryu, J. Seo and S. I. Seok, Nature, 2015, 517, 476-480.

31. N. Pellet, P. Gao, G. Gregori, T. Y. Yang, M. K. Nazeeruddin, J. Maier and M. Gratzel, Angew. Chem., 2014, 53, 3151-3157.

32. G. E. Eperon, S. D. Stranks, C. Menelaou, M. B. Johnston, L. M. Herz and H. J. Snaith, Energ. Environ. Sc., 2014, 7, 982-988.

33. S. Wozny, M. Yang, A. M. Nardes, C. C. Mercado, S. Ferrere, M. O. Reese, W. Zhou and K. Zhu, Chemistry of Materials, 2015, DOI: 10.1021/acs.chemmater.5b01691.

34. S. Aharon, A. Dymshits, A. Rotem and L. Etgar, J. Mater. Chem. A, 2015, 3, 9171-9178.

35. M. Hu, L. Liu, A. Mei, Y. Yang, T. Liu and H. Han, J. Mater. Chem. A, 2014, 2, 1711517121.

36. M. I. Saidaminov, A. L. Abdelhady, B. Murali, E. Alarousu, V. M. Burlakov, W. Peng, I. Dursun, L. Wang, Y. He, G. Maculan, A. Goriely, T. Wu, O. F. Mohammed and O. M. Bakr, Nat. Commun., 2015, 6, 7586.

37. Y. Dang, Y. Liu, Y. Sun, D. Yuan, X. Liu, W. Lu, G. Liu, H. Xia and X. Tao, CrystEngComm., 2015, 17, 665-670.

38. T. Zhang, M. Yang, E. E. Benson, Z. Li, J. van de Lagemaat, J. M. Luther, Y. Yan, K. Zhu and Y. Zhao, Chem. Commun., 2015, 51, 7820-7823.

39. J. M. Kadro, K. Nonomura, D. Gachet, M. Grätzel and A. Hagfeldt, Sci. Rep., 2015, 5, 11654.

40. O. Söhnel and P. Novotný, Densities of Aqueous Solutions of Inorganic Substances, Elsevier, Amsterdam, 1985.

41. M. T. Weller, O. J. Weber, J. M. Frost and A. Walsh, J. Phys. Chem. Let. 2015, 6, 32093212. 
42. J. S. Manser, B. Reid and P. V. Kamat, J. Phys. Chem. C, 2015, 119, 17065-17073.

43. F. C. Hanusch, E. Wiesenmayer, E. Mankel, A. Binek, P. Angloher, C. Fraunhofer, N. Giesbrecht, J. M. Feckl, W. Jaegermann, D. Johrendt, T. Bein and P. Docampo, J. Phys. Chem. Lett., 2014, 5, 2791-2795.

44. T. M. Koh, K. Fu, Y. Fang, S. Chen, T. C. Sum, N. Mathews, S. G. Mhaisalkar, P. P. Boix and T. Baikie, J. Phys. Chem. C, 2014, 118, 16458-16462. 